\title{
Initial Cerebellar Ataxia in Hereditary Adult-Onset Primary Lateral Sclerosis
}

\author{
José Gazulla ${ }^{a}$ Silvia Izquierdo-Alvarez ${ }^{b} \quad$ Emilio Ruiz-Fernández ${ }^{a}$ \\ José Bercianoc \\ aDepartment of Neurology, Hospital Universitario Miguel Servet, Zaragoza, Spain; \\ bSection of Genetics, Department of Clinical Biochemistry, Hospital Universitario \\ Miguel Servet, Zaragoza, Spain; 'Department of Neurology, Hospital Universitario \\ Marqués de Valdecilla (IDIVAL), University of Cantabria, CIBERNED, Santander, Spain
}

\section{Keywords}

Primary lateral sclerosis - Cerebellar ataxia - Hereditary adult-onset primary lateral sclerosis . Inaugural cerebellar ataxia

\begin{abstract}
Cerebellar ataxia preceding the apparition of primary lateral sclerosis (PLS) is reported herein. Three individuals from 2 independent kindreds experienced ataxia before developing clinical signs of PLS. Disease onset was during the sixth decade or later, and an insidious onset, with progression exceeding 11 years, was observed. Pathochrony was homogenous, consisting of initial gait instability, followed by hand dysmetria 2 years later. During a 5-year followup, cerebellar ataxia remained the sole clinical manifestation, preceding the appearance of muscle stiffness, which progressed to a paraparesis, and then to a purely spastic quadriparesis, over 4 years; pseudobulbar dysarthria and dysphagia appeared later. At this disease stage, limb spasticity, hyperactive jaw and limb stretch reflexes, extensor plantar responses, and a spastic dysarthria were found on examination; limb dysmetria and an ataxo-spastic gait were also found. No muscle atrophy or fasciculation was observed. Among ancillary tests, electromyographic studies performed 6 years after disease onset revealed normal motor unit action potentials and absence of spontaneous activity, in 2 individuals. MRI revealed normal cerebellum and brainstem in 2 cases. Inheritance was dominant in both kindreds, and extensive genetic testing was negative. It is concluded that cerebellar ataxia preceded the appearance of a purely spastic spinobulbar syndrome (which fulfilled the clinical diagnostic criteria for PLS) during a 5-year period in 3 patients with a hereditary, adult-onset form of PLS; subsequent disease progression was equivalent to that of sporadic PLS. Further studies are needed to fully delineate the clinical and genetic spectra of adult-onset PLS.
\end{abstract}




\section{Introduction}

Adult-onset primary lateral sclerosis (PLS) is a degenerative disease caused by gradual loss of upper motor neurons. It is not considered a hereditary disease according to clinical diagnostic criteria [1,2], although there is evidence about inherited cases of PLS, which are much rarer than sporadic ones.

Cerebellar ataxia is not supposed to form part of the PLS-plus spectrum, either [1]. However, considerable cerebellar gray and white matter involvement was evidenced by $3 \mathrm{~T}$ MRI in PLS, concluding that the cerebellar involvement could be clinically patent in PLS [3]; this hypothesis was corroborated by clinical observation in 2 individuals [4]. The aim of this article was to describe the clinical course of inaugural cerebellar ataxia in 3 individuals with hereditary adult-onset PLS, coming from 2 independent kindreds.

\section{Methods and Patients}

The pedigrees of the families under study are represented in Figure 1. Kindred A comprised 10 affected individuals over 3 generations, who displayed a similar spastic spinobulbar syndrome; the proband was sequentially evaluated over 11 years by one of us (J.G.). An association between PLS and progressive nonfluent aphasia was reported in kindred B [5], in addition to the manifestations described herein. Written informed consent was obtained

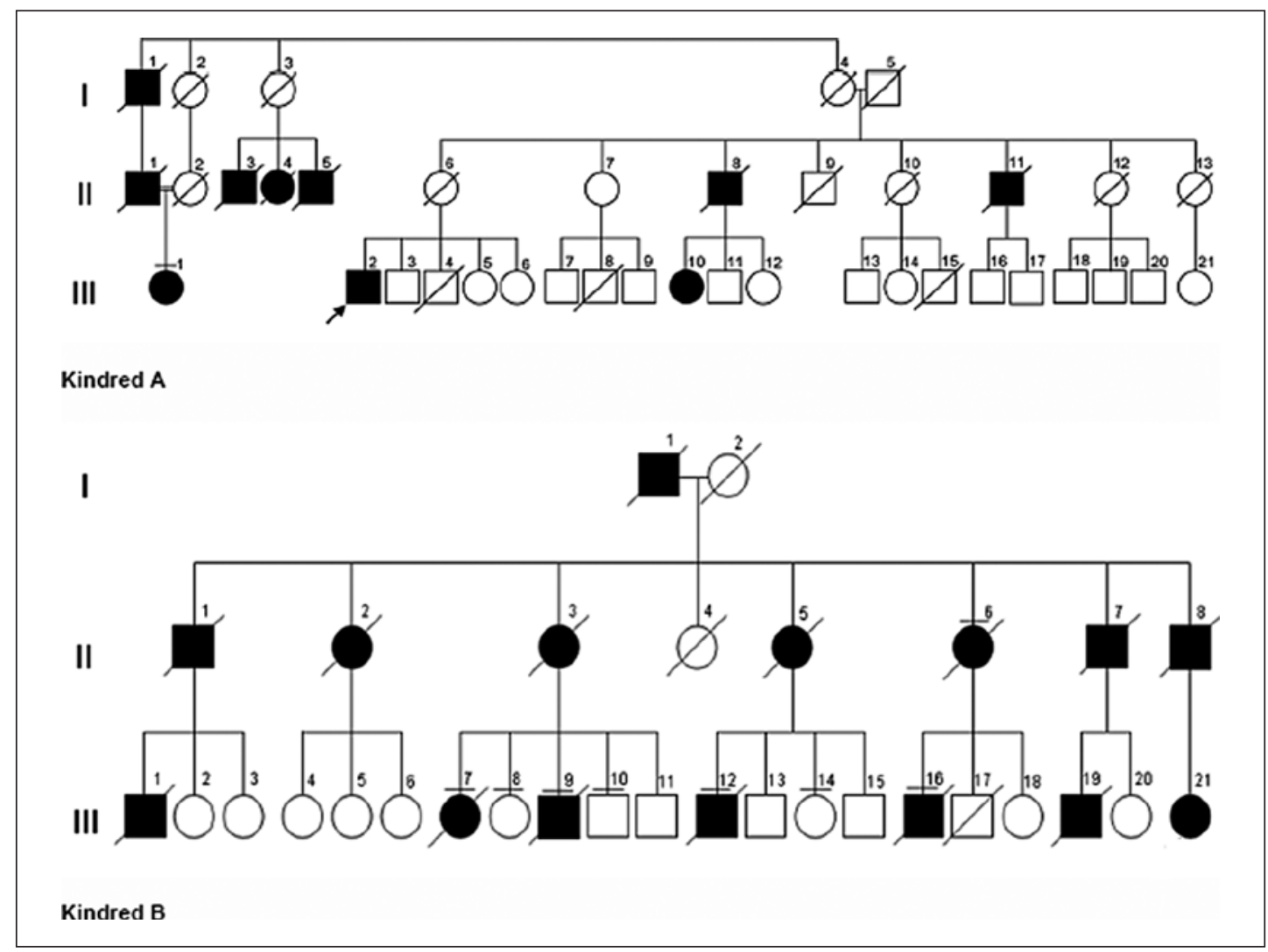

Fig. 1. Pedigrees of families. Horizontal bar indicates clinically examined; arrow indicates the proband; slash lines indicate the deceased individual. Squares are male, and circles are female. Filled symbols indicate affected subjects and empty symbols, unaffected subjects. 
from the patients, or from their next of kin in case of decease, for publication of this case report and any accompanying video recording. This study was made in accordance with the local Institutional Ethics Committee and the 1964 Declaration of Helsinki.

\section{Clinical Studies}

Case A III-2 (Proband)

A 67-year-old man developed progressive gait unsteadiness and, 2 years later, hand dysmetria. On examination at 70 years, muscle tone was normal, tendon reflexes were grade $3 / 4$, and plantar responses were flexor. Gait was wide-based, with tandem gait limited to 5 steps. Mild dysmetria in the finger-to-nose and heel-to-shin tests was found. At age 72 years, spasticity was detected in the legs, and at 74 , in the arms.

At age 76 years, dysarthria became apparent. Spasticity was mild in the upper limbs and moderate in the lower ones. Tendon reflexes were grade $3 / 4$ with ankle clonus, and plantar responses were indifferent. His gait was mildly ataxo-spastic, and limb dysmetria was moderate. Dysarthric speech was noted.

At age 79 years, 12 years after disease onset, spasticity was moderate in the arms and severe in the legs. The masseter reflex was brisk, there was clonus in upper and lower limb stretch reflexes, and plantar responses were extensor. Muscle bulk and strength remained normal, without fasciculation. A moderate ataxo-spastic gait was observed, with tandem gait limited to one step (see online suppl. material at www.karger.com/doi/10.1159/000515157). Sensation was preserved. Moderate limb dysmetria and spastic dysarthria were found. Eye movements were full, without nystagmus or altered ocular pursuit.

Case B III-7

A previously healthy woman developed wide-based gait, aged 70 years. Gradually, increasing hand dysmetria became apparent later. Five years after disease onset, muscle stiffness appeared in the legs and later in the arms, together with painful spasms in the limbs and trunk. Joint contractures developed, and she became bedridden. Pseudobulbar affect, dysarthria, and dysphagia ensued 10 years after disease onset. The patient died aged 85 years.

On examination 5 months before death, there was a spastic quadriparesis with flexion contractures at the shoulders, elbows, wrists, hips, and knees. Muscle volume was normal, without fasciculation. Jaw and limb stretch reflexes were hyperactive, with ankle clonus, and plantar responses were extensor. Pain and vibration sense was preserved. Finger-to-nose and heel-to-shin maneuvers could not be assessed, due to joint contractures. Eye movements were full, without nystagmus. Speech was effortful and hypophonic. Autopsy findings of case B III-7 were reported previously [5].

Case B III-21

A 67-year-old woman experienced progressive unsteady and wide-based gait at the age of 56 years, accompanied by hand dysmetria 2 years later. Five years after the disease onset, stiffness appeared in the lower limbs, 2 years later in the upper limbs, and 9 years after disease onset, dysarthria and dysphagia were added.

On examination, spasticity was found in the hips and knees (Ashworth Scale grade 3), together with hyperactive masseter and limb stretch reflexes, ankle clonus, and extensor plantar responses. Muscle bulk and strength were normal, without fasciculation. Stance was wide-based, the Romberg test was negative, gait was ataxo-spastic requiring support, and tandem gait was impossible. Sensation was intact to pinprick, joint position, and vibration. There was final tremor and dysmetria in the finger-to-nose and heel-to-shin maneuvers. Eye movements were full, with no nystagmus. A spastic dysarthria was noted.

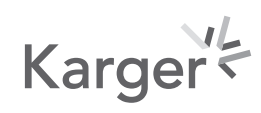




\section{Results}

\section{Electrophysiological Studies}

In case A III-2, an electromyogram performed 10 years after disease onset revealed normal motor unit action potentials and absence of spontaneous activity in upper limb, lower limb, paraspinal, and masseter muscles. Nerve conduction and EMG studies in subject B III-21, performed 6 years after disease onset revealed normal findings; no spontaneous muscle activity was recorded.

\section{Imaging Studies}

Conventional 1.5 T MRI studies, performed 4 and 9 years after disease onset, disclosed very mild, nonprogressive atrophy of the superior cerebellar vermis and dilation of the primary fissure in patient A III-2. In case B III-21, conventional cranial 1.5 T MRI, performed 6 and 7 years after disease onset, revealed normal cerebellar and brainstem structures, and a thin corpus callosum.

Genetic Studies

Case A III-2

A study performed with triplet repeat primed PCR of dominant spinocerebellar ataxia (SCA) types 1, 2, 3, 6, 7, 8, and 17; dentatorubral-pallidoluysian atrophy, Friedreich's ataxia, and fragile-X tremor ataxia syndrome was negative, and so were dynamic expansions in C9orf72; multiplex ligation-dependent probe amplification aimed at the hereditary spastic paraplegia (HSP) genes: SPAST, NIPA1, SPG7, REEP1, ATL1, and PLP1; and next-generation sequencing (NGS) panels aimed at HSP (10 genes). Whole exome sequencing was performed using SureSelectXT libraries sequenced into a NovaSeq 6000 System (Illumina). Bioinformatics analysis, performed on a virtual panel of 5713 OMIM genes, was also negative.

\section{Case BI-II-7}

A panel aimed at PLS (24 genes); microarray-based comparative, genomic hybridization to detect deletions in genes involved in PLS, especially TBK1; and massive sequencing of the human genome carried out to identify the following: (1) single-nucleotide and insertiondeletion variants included in exonic regions, 3'UTR and 5'UTR regions, and all intron variants described as probably pathogenic, or pathogenic, in the ClinVar database (v20150330), and (2) copy number variations in exonic, intronic or intergenic regions, did not render pathogenic variants associated with the object of consultation.

Case BI-II-21

A molecular study performed with triplet repeat primed PCR of SCA 1, 2, 3, 6, 7, 8, 10, 12, and 17 and dentatorubral-pallidoluysian atrophy was negative. Dynamic expansions in C9orf72 were ruled out, as was the presence of large deletions/duplications (multiplex ligation-dependent probe amplification) in MAPT and GRN.

An NGS study of the human exome in 145 genes associated with ataxia and HSP did not reveal pathogenic variants, or variants of unknown significance. An extension made to the clinical exome study by NGS (5,713 genes) was negative. 


\section{Discussion}

The core clinical feature in this series was a purely spastic spinobulbar paresis, predated by isolated cerebellar ataxia; inheritance was dominant. Disease onset was during the sixth decade or later. An insidious start and a protracted, unrelenting progression exceeding 11 years took place in every case. Disease pathochrony was homogeneous, characterized by initial gait instability, followed by hand dysmetria 2 years later. During 5 years, cerebellar ataxia was the only clinical manifestation. Along the next 4 years, lower limb muscle stiffness appeared and evolved into a paraparesis, and then into a purely spastic, symmetric quadriparesis. Pseudobulbar dysarthria and dysphagia unveiled afterward. At this stage, cerebellar symptoms had become clinically irrelevant due to the severity of the spastic syndrome.

The described upper motor neuron manifestations fulfilled the clinical diagnostic criteria of PLS [1, 2]: (1) insidious onset of spastic paresis beginning in the lower extremities; (2) onset in the fifth decade or later; (3) gradually progressive course (duration $\geq 3$ years); (4) clinical findings limited to corticospinal dysfunction; and (5) symmetrical distribution, ultimately developing spastic spinobulbar paresis. Criterion number 3 (absence of the family history) was not met. Consensus diagnostic criteria for definite PLS were also met in cases A III-2 and B III-21 [6]. Moreover, the absence of lower motor neuron signs in EMG studies >4 years after disease onset excluded amyotrophic lateral sclerosis (ALS) in the same cases [7].

Age at onset and disease duration in this series were equivalent to those reported in sporadic PLS. Spread of spasticity in the ascending subtype of PLS was described as steady, extending from lower to upper limbs, then to cranial regions, the interval between onset of lower limb and bulbar symptoms being 5 years [8]. The spread of spasticity and an interval over 4 years between lower limb and bulbar symptoms observed in this study, were also similar to those of sporadic PLS.

Adult-onset PLS is usually considered a sporadic disease [9]. However, Erb and other early authors claimed that PLS could be hereditary [10-12]. Recent reports of adult-onset dominant PLS are limited to one kinship with a heterozygote mutation in SPG7 [13]; a FrenchCanadian family, in which a locus was identified on chromosome 4 [14, 15]; a family with a missense TBK1 mutation presenting with PLS and primary progressive aphasia [16]; and kindred B, in which no molecular diagnosis was obtained [5].

A dominant transmission was observed in both study kindreds. By history, the proband's mother (A II-6) and maternal grandmother (A I-4), obligate carriers deceased at 95 and 100 years, respectively, did not develop a spastic spinobulbar syndrome, a fact suggestive of noncomplete penetrance. On the opposite, penetrance was complete in kindred B.

Extensive molecular testing proved negative in every study member, but it must be considered that a specific genetic marker for adult-onset PLS is not available at present: mutations in ALS2 do not cause adult-onset PLS [17], although instances of it may occur within ALS pedigrees, such as those associated with variants in TBK1 and UBQLN2 [18, 19]. Apparently sporadic cases have been linked to KIF5A, KIF1A, SYNE2, C9orf72, SPG7, PARK2, DCTN1, and other genes $[6,20]$. No variant in any of those genes was found in this study. Contrariwise, juvenile PLS may be inherited in a recessive mode, the causal mutant genes being ERLIN2 on chromosome 8p11.21-p12 [21] and alsin on chromosome 2q33.1, which may also cause infantile-onset ascending spastic paralysis and a juvenile form of ALS [22-24].

Cerebellar ataxia has seldom been reported in PLS: it was observed in one member from a family with dominant adult-onset PLS linked to SPG7 [13]; intention tremor and unsteady gait were found in 2 members expressing PLS in a kindred with motor neuron disease [25]. PLS patients have been found to have a loss of Purkinje cells in necropsy studies [5, 25], and abnormalities in dentate-rubro-thalamo-cortical and spinocerebellar tracts, and in cerebellar white matter, in MRI studies $[3,26]$.

\section{Karger'}


Cerebellar symptom progression was uniform and progressive in our patients: initial gait unsteadiness, followed by hand dysmetria 2 years later. The cerebellar syndrome remained isolated during 5 years, until a spastic spinobulbar syndrome gradually developed, albeit limb dysmetria and an ataxo-spastic gait were still recognizable on examination at that stage.

The described clinical course, in which initial cerebellar ataxia was later joined by a spastic spinobulbar syndrome, resembles the cerebellar variety of progressive supranuclear palsy (PSP), in which ataxia may antedate the cardinal features of the disease by many years [27]. Hence, the presence of isolated cerebellar signs might lead to misdiagnosis in early stages of PLS and PSP. Besides, pathologically demonstrated PSP may present clinically as isolated PLS [28].

Differential diagnosis of dominantly inherited PLS associated with cerebellar ataxia includes complex types of HSP, even though these do not exhibit bulbar muscle involvement as our patients did, and SCA 1, SCA 2, SCA 3, SCA 17, SCA 36, and adult-onset Alexander disease, because these diseases may display spasticity, besides cerebellar ataxia [29-33]; these entities were ruled out by molecular studies in the study patients. In addition, our cases did not display cerebellar atrophy on MRI, a characteristic finding in dominant spinocerebellar ataxia.

\section{Conclusions}

To summarize, there is clinical $[5,13-16]$ and neuropathological evidence $[5,16]$ that demonstrates the existence of hereditary, adult-onset PLS. This should not be surprising since juvenile PLS may also be inherited. Besides, additions to the range of PLS-plus manifestations, such as cerebellar ataxia, might be possible. Further research is needed to fully elucidate the clinical and genetic spectra of PLS.

\section{Acknowledgement}

Our thanks to Mrs. María Berciano Fernández for edition of the online suppl. material and to Mrs. Teresa Sopeña Biarge and Mrs. Mar González-Cantalejo, from the Medical Library of Hospital Universitario Miguel Servet.

\section{Statement of Ethics}

Guidelines were followed in accordance with the World Medical Association Declaration of Helsinki, and the Hospital Universitario Miguel Servet institutional Ethics Committee. Informed written consent was obtained for every test performed. Written informed consent was obtained from the patients, or from their next of kin in case of decease, for publication of this case report and any accompanying video recording.

\section{Conflict of Interest Statement}

The authors have no conflicts of interest to declare. 
Gazulla et al.: Cerebellar Ataxia in Primary Lateral Sclerosis

\section{Funding Sources}

No funding was received for the elaboration of this original article.

\section{Author Contributions}

J. Gazulla: (1) conception and design of the work, acquisition, analysis, and interpretation the data; (2) drafted the work and revised it critically for important intellectual content; approved the version to be published; (3) agreed to be accountable for all aspects of the work in ensuring that questions related to the accuracy or integrity of any part of the work are appropriately investigated and resolved. S. Izquierdo-Alvarez: (1) acquisition, analysis, and interpretation of data; (2) drafted a part of the work and revised it critically for the important intellectual content; approved the version to be published; (3) agreed to be accountable for all aspects of the work in ensuring that questions related to the accuracy or integrity of any part of the work are appropriately investigated and resolved. E. Ruiz-Fernández: (1) acquisition and interpretation of data; (2) revised the manuscript critically for important intellectual content; approved the version to be published; and (3) agreed to be accountable for all aspects of the work in ensuring that questions related to the accuracy or integrity of any part of the work are appropriately investigated and resolved. J. Berciano: (1) conception of work, and acquisition and analysis of data; (2) drafted a part of the work and revised it critically for important intellectual content; approved the version to be published; and (3) agreed to be accountable for all aspects of the work in ensuring that questions related to the accuracy or integrity of any part of the work are appropriately investigated and resolved.

\section{References}

1 Singer MA, Statland JM, Wolfe GI, Barohn RJ. Primary lateral sclerosis. Muscle Nerve. 2007;35:291-302.

2 Pringle CE, Hudson AJ, Muñoz DG, Kiernan JA, Brown WF, Ebers GC. Primary lateral sclerosis. Clinical features, neuropathology and diagnostic criteria. Brain. 1992;115(Pt 2):495-520.

3 Finegan E, Chipika RH, Li Hi Shing S, Doherty MA, Hengeveld JC, Vajda A, et al. The clinical and radiological profile of primary lateral sclerosis: a population-based study. J Neurol. 2019;266:2718-33.

4 Gazulla J, Ferrer I, Berciano J. The clinical and radiological profile of primary lateral sclerosis: an annotation on its pathological and clinical background. J Neurol. 2020;267:574.

5 Gazulla J, Ferrer I, Izquierdo-Alvarez S, Alvarez S, Sánchez-Alcudia R, Bestué-Cardiel M, et al. Hereditary primary lateral sclerosis and progressive nonfluent aphasia. J Neurol. 2019;266:1079-90.

6 Turner MR, Barohn RJ, Corcia P, Fink JK, Harms MB, Kiernan MC, et al. Primary lateral sclerosis: consensus diagnostic criteria. J Neurol Neurosurg Psychiatry. 2020;91:373-7.

7 Gordon PH, Cheng B, Katz IB, Pinto M, Hays AP, Mitsumoto H, et al. The natural history of primary lateral sclerosis. Neurology. 2006;66:647-53.

8 Floeter MK, Mills R. Progression in primary lateral sclerosis: a prospective analysis. Amyotroph Lateral Scler. 2009;10:339-46.

9 Statland JM, Barohn RJ, Dimachkie MM, Floeter MK, Mitsumoto H. Primary lateral sclerosis. Neurol Clin. 2015; 33:749-60.

10 Erb W. Spastic and syphilitic spinal paralysis. Lancet. 1902;2:969-74.

11 Price GE. Familial lateral sclerosis (spastic paralysis). J Nerv Ment Dis. 1939;90(1):51-5.

12 Stark FM, Moersch FP. Primary lateral sclerosis. A distinct clinical entity. J Nerv Ment Dis. 1945;102:332-7.

13 Liu Y, Xu J, Tao W, Fu C, Liu J, Yu R, et al. Exome sequencong identifies a mutation (Y740C) in spastic paraplegia 7 gene associated with adult-onset primary lateral sclerosis in a chinese family. Eur Neurol. 2019;81:87-93.

14 Dupré N, Valdmanis PN, Bouchard JP, Rouleau GA. Autosomal dominant primary lateral sclerosis. Neurology. 2004;68:1156-7.

15 Valdmanis PN, Dupré N, Rouleau GA. A locus for primary lateral sclerosis on chromosome 4ptel-4p16.1. Arch Neurol. 2008;65:383-6.

16 Hirsch-Reinshagen V, Alfaify OA, Hsiung GR, Pottier C, Baker M, Perkerson R, et al. Clinicopathologic correlations in a family with a TBK1 mutation presenting as primary progressive aphasia and primary lateral sclerosis. Amyotroph Lateral Scler Frontotemporal Degener. 2019;20:568-75. 
17 Brugman F, Eymard-Pierre E, van den Berg LH, Wokke JH, Gauthier-Barichard F, Boespflug-Tanguy 0. Adultonset primary lateral sclerosis is not associated with mutations in the ALS2 gene. Neurology. 2007;69: 702-4.

18 Gómez-Tortosa E, Van der Zee J, Ruggiero M, Gijselinck I, Esteban-Pérez J, García-Redondo A, et al. Familial primary lateral sclerosis or dementia associated with Arg573Gly TBK1 mutation. J Neurol Neurosurg Psychiatry. 2017;88:996-7.

19 Yamashita S, Ando Y. Genotype-phenotype relationship in hereditary amyotrophic lateral sclerosis. Transl Neurodegener. 2015;4:13.

20 Mitsumoto H, Nagy PL, Gennings C, Murphy J, Andrews H, Goetz R, et al. Phenotypic and molecular analyses of primary lateral sclerosis. Neurol Genet. 2015;1:e3.

21 Al-Saif A, Bohlega S, Al-Mohanna F. Loss of ERLIN2 function leads to juvenile primary lateral sclerosis. Ann Neurol. 2012;72:510-6.

22 Helal M, Mazaheri N, Shalbafan B, Malamiri RA, Dilaver N, Buchert R, et al. Clinical presentation and natural history of infantile-onset ascending spastic paralysis from three families with an ALS2 founder variant. Neurol Sci. 2018;39:1917-25.

23 Mintchev N, Zamba-Papanicolaou E, Kleopa KA, Christodoulou K. A novel ALS2 splice-site mutation in a cypriot juvenile-onset primary lateral sclerosis family. Neurology. 2009;72:28-32.

24 Panzeri C, De Palma C, Martinuzzi A, Daga A, De Polo G, Bresolin N, et al. The first ALS2 missense mutation associated with JPLS reveals new aspects of alsin biological function. Brain. 2006;129:1710-9.

25 Polvikoski TM, Murray A, Harper PS, Neal JW. Familial motor neuron disease with dementia: phenotypic variation and cerebellar pathology. J Neurol Neurosurg Psichiatry. 2003;74:1516-20.

26 Tu S, Menke RAL, Talbot K, Kiernan MC, Turner MR. Cerebellar tract alterations in PLS and ALS. Amyotroph Lateral Scler Frontotemporal Degener. 2019;20:281-4.

27 Kanazawa M, Shimohata T, Toyoshima Y, Tada M, Kakita A, Morita T, etal. Cerebellar involvement in progressive supranuclear palsy: a clinicopathological study. Mov Disord. 2009;24:1312-8.

28 Nagao S, Yokota O, Nanba R, Takata H, Haraguchi T, Ishizu H, et al. Progressive supranuclear palsy presenting as primary lateral sclerosis but lacking parkinsonism, gaze palsy, aphasia, or dementia. J Neurol Sci. 2012;323: 147-53.

29 Matilla-Dueñas A, Goold R, Giunti P. Clinical, genetic, molecular, and pathophysiological insights into spinocerebellar ataxia type 1. Cerebellum. 2008;7:106-14.

30 Van Gaalen J, Giunti P, van de Warrenburg BP. Movement disorders in spinocerebellar ataxias. Mov Disord. 2011;26:792-800.

31 De Bot S, Willemsen MAAP, Vermeer S, Kremer HPH, van de Warrenburg BP. Reviewing the genetic causes of spastic-ataxias. Neurology. 2012;79:1507-14.

32 García-Murias M, Quintáns B, Arias M, Seixas AI, Cacheiro P, Tarrío R, et al. Costa da Morte' ataxia is spinocerebellar ataxia 36: clinical and genetic characterization. Brain. 2012;135:1423-35.

33 Sugihara K, Maruyama H, Morino H, Miyamoto R, Ueno H, Matsumoto M, et al. The clinical characteristics of spinocerebellar ataxia 36: a study of 2121 Japanese ataxia patients. Mov Disord. 2012;27:1158-63. 